\title{
ChIP-less analysis of chromatin states
}

\author{
Zhangli Su, ${ }^{1,2}$, Melissa D Boersma ${ }^{2,3}$, Jin-Hee Lee ${ }^{1,2}$, Samuel S Oliver ${ }^{1,2}$, Shichong Liư ${ }^{4}$, Benjamin A Garcia ${ }^{4}$ \\ and John M Denu $u^{1,2^{*}}$
}

\begin{abstract}
Background: Histone post-translational modifications (PTMs) are key epigenetic regulators in chromatin-based processes. Increasing evidence suggests that vast combinations of PTMs exist within chromatin histones. These complex patterns, rather than individual PTMs, are thought to define functional chromatin states. However, the ability to interrogate combinatorial histone PTM patterns at the nucleosome level has been limited by the lack of direct molecular tools.

Results: Here we demonstrate an efficient, quantitative, antibody-free, chromatin immunoprecipitation-less (ChIP-less) method for interrogating diverse epigenetic states. At the heart of the workflow are recombinant chromatin reader domains, which target distinct chromatin states with combinatorial PTM patterns. Utilizing a newly designed combinatorial histone peptide microarray, we showed that three reader domains (ATRX-ADD, ING2-PHD and AIRE-PHD) displayed greater specificity towards combinatorial PTM patterns than corresponding commercial histone antibodies. Such specific recognitions were employed to develop a chromatin reader-based affinity enrichment platform (matrix-assisted reader chromatin capture, or MARCC). We successfully applied the reader-based platform to capture unique chromatin states, which were quantitatively profiled by mass spectrometry to reveal interconnections between nucleosomal histone PTMs. Specifically, a highly enriched signature that harbored H3K4me0, H3K9me2/3, H3K79meO and H4K2Ome2/3 within the same nucleosome was identified from chromatin enriched by ATRX-ADD. This newly reported PTM combination was enriched in heterochromatin, as revealed by the associated DNA.

Conclusions: Our results suggest the broad utility of recombinant reader domains as an enrichment tool specific to combinatorial PTM patterns, which are difficult to probe directly by antibody-based approaches. The reader affinity platform is compatible with several downstream analyses to investigate the physical coexistence of nucleosomal PTM states associated with specific genomic loci. Collectively, the reader-based workflow will greatly facilitate our understanding of how distinct chromatin states and reader domains function in gene regulatory mechanisms.
\end{abstract}

Keywords: Affinity enrichment, Antibody-free, Chromatin, Histone, Peptide microarray, PTM, Reader domain

\section{Background}

Post-translational modifications (PTMs) on histones constitute an intricate 'language' that instructs chromatinbased processes [1]. Different histone PTMs deposited across multiple residues on histone proteins generate a combinatorial pattern. The number of combinations can be further amplified by the presence of two copies of each

\footnotetext{
* Correspondence: jmdenu@wisc.edu

'Department of Biomolecular Chemistry, University of Wisconsin, Madison, WI 53706, USA

${ }^{2}$ Wisconsin Institute for Discovery, University of Wisconsin, Madison, WI 53715, USA

Full list of author information is available at the end of the article
}

histone (H3, H4, H2A and H2B) within a nucleosome. One intriguing hypothesis is that PTM combinations better categorize unique chromatin states than an assessment of an individual PTM. Evidence of the importance of combinatorial PTMs comes from studies on embryonic stem cells, where the coexistence of 'active mark' H3K4me3 and 'repressive mark' H3K27me3 at differentiation-related gene promoters poises genes for subsequent regulation [2]. Also, the coexistence of H3S10ph and H3K9me3 is a signal to evict heterochromatin protein 1 during the $\mathrm{M}$ phase [3]. How combinatorial PTM patterns reflect specific chromatin states or biological processes 
remains incompletely understood. Decoding the enormous combinatorial capacity of PTM patterns $[4,5]$ has been hindered by a lack of proper tools to distinguish different combinatorial PTM patterns.

Current methodologies to define chromatin states rely almost exclusively on histone antibodies, which have been developed to recognize individual PTMs. As summarized in Table 1, each of these approaches has its own limitations for analysis of the combinatorial histone PTM patterns. Proper interpretation of such analyses relies on a thorough understanding of the specificity of these antibodies. However, recent studies reveal crossreactivity to unexpected antigens ('off-targets') of many commercial histone antibodies [6-11]. Lot-to-lot variability, high costs and engineering difficulties are critical concerns for the development and commercialization of histone antibodies [12,13]. All these have challenged the use of histone antibodies in accurately probing chromatin states. Therefore an antibody-free approach to directly enrich combinatorial PTM patterns that maintains native nucleosome structure and combinatorial PTM complexity for downstream quantitation and genome mapping of physical intranucleosomal PTM connections will greatly simplify attempts to characterize chromatin states.

To address this bottleneck, we developed an epigenetic platform utilizing 'reader' domains to enrich, identify and quantify chromatin states. Reader domains are a diverse collection of histone-interacting protein modules that can interpret histone PTM language in cells [23]. Previously, we and other groups described the ability of reader domains to discriminate combinatorial PTM patterns [24,25], suggesting their potential for probing native chromatin states. Using three readers as proof of concept, we demonstrated a powerful workflow involving a combinatorial PTM histone peptide microarray and a reader-based affinity enrichment platform (matrixassisted reader chromatin capture, or MARCC) to capture and quantify chromatin states maintained on native nucleosomes.

\section{Results and discussion}

The chromatin affinity enrichment requires highly specific 'baits' that can distinguish different PTM states, making readers such as malignant brain tumor domains unsuitable for such application due to their insensitivity to residues surrounding the targeted methyl lysine group [26]. Three reader domains were selected (Additional file 1: Figure S1) based on their reported chromatin-binding specificities: plant homeodomain (PHD) zinc fingers from ING2 and AIRE, and the ADD (ATRX-DNMT3ADNMT3L) domain from ATRX [27-32]. To evaluate the specificity of reader domains systematically, we designed a histone peptide library that featured a more comprehensive collection of histone peptides than previous platforms [6,7] (compared in Table 2). The new library contained 746 tiled peptide species, $\approx 60 \%$ of which comprised new PTMs or novel combinations (Figure 1A and Additional file 2). Such extensive PTM combinations were critical in evaluating the effects of combinatorial PTM patterns on reader binding specificity.

Reader domains were recombinantly expressed and purified as HaloTag fusions, which permitted sensitive detection by covalent labeling with fluorescence [36] when screened on microarrays containing $\approx 4,500$ peptides (Figure 1B). An additional fluorescence dye was introduced during peptide printing to enable dual-channel fluorescence detection (532 nm/635 nm) and allowing easy identification of misprinting (Figure 1C). Binding events were quantified from fluorescence signal intensities at $635 \mathrm{~nm}$ of spatially addressed peptides. Each peptide was printed six times on each microarray for statistical analysis and proper control peptides were included in each subarray (Figure 1C). For comparison, two ChIP-grade commercial antibodies for H3K9me3 and H3K4me3 were analyzed using the microarrays.

Microarray analysis revealed high selectivity for aminoacid sequence and combinatorial PTM states with reader domains (for complete dataset, see Additional file 3). Sequence specificity was assessed by comparing binding signals for a panel of methylated or unmodified peptides

Table 1 Comparison between different methodologies for analyzing chromatin states with combinatorial histone PTMs

\begin{tabular}{|c|c|c|c|c|c|c|}
\hline & $\begin{array}{c}\text { Analysis of more } \\
\text { than two } \\
\text { PTM states }\end{array}$ & $\begin{array}{c}\text { Analysis of direct } \\
\text { intranucleosomal } \\
\text { connection }\end{array}$ & $\begin{array}{c}\text { Ability to enrich } \\
\text { combinatorial } \\
\text { PTMs }\end{array}$ & $\begin{array}{c}\text { Ability to quantify } \\
\text { combinatorial } \\
\text { PTMs }\end{array}$ & $\begin{array}{l}\text { Ability to map } \\
\text { combinatorial PTMs } \\
\text { to the genome }\end{array}$ & Antibody -free \\
\hline $\begin{array}{l}\text { MARCC-quantitative mass } \\
\text { spectrometry (this report) }\end{array}$ & $\checkmark$ & $\checkmark$ & $\checkmark$ & $\checkmark$ & $\checkmark$ & $\checkmark$ \\
\hline $\begin{array}{l}\text { Overlaying ChIP-sequencing } \\
\text { tracks [14-18] }\end{array}$ & $\checkmark$ & & & & $\checkmark$ & \\
\hline ChIP-re-ChIP $[19,20]$ & & $\checkmark$ & $\checkmark$ & & $\checkmark$ & \\
\hline $\begin{array}{l}\text { ChIP-quantitative mass } \\
\text { spectrometry }[2,21,22]\end{array}$ & $\checkmark$ & $\checkmark$ & & $\checkmark$ & & \\
\hline $\begin{array}{l}\text { Middle-down histone mass } \\
\text { spectrometry [4] }\end{array}$ & $\checkmark$ & $\begin{array}{c}\mathcal{J} \text { (within one } \\
\text { histone tail) }\end{array}$ & & $\checkmark$ & & $\checkmark$ \\
\hline
\end{tabular}


Table 2 Comparison between different platforms of histone peptide microarrays

\begin{tabular}{|c|c|c|c|c|}
\hline Platforms & & $\begin{array}{l}\text { Combinatorial PTM histone peptide } \\
\text { microarray (this report) }\end{array}$ & $\begin{array}{l}\text { MODified histone peptide array } \\
\text { (Active Motif) }[7,33]\end{array}$ & $\begin{array}{c}\text { EpiGOLD histone peptide array } \\
\text { (EpiCypher) }[6,34,35]\end{array}$ \\
\hline Array coating & & Nitrocellulose & Nitrocellulose & Streptavidin \\
\hline \multirow[t]{6}{*}{ Peptide coverage } & Single PTMs & $\begin{array}{c}169 \text { peptides covering } 61 \text { sites } \\
\text { of } \mathrm{H} 3, \mathrm{H} 4, \mathrm{H} 2 \mathrm{~A} \text { and } \mathrm{H} 2 \mathrm{~B}\end{array}$ & $\begin{array}{l}70 \text { peptides covering } 37 \text { sites of } \\
\mathrm{H} 3, \mathrm{H} 4, \mathrm{H} 2 \mathrm{~A} \text { and } \mathrm{H} 2 \mathrm{~B} \text { ( } \mathrm{N} \text {-term) }\end{array}$ & $\begin{array}{c}70 \text { peptides covering } 28 \text { sites } \\
\text { of } \mathrm{H} 3, \mathrm{H} 4, \mathrm{H} 2 \mathrm{~A} \text { and } \mathrm{H} 2 \mathrm{~B}\end{array}$ \\
\hline & $\begin{array}{l}\text { Combinatorial } \\
\text { PTMs }\end{array}$ & 371 peptides containing up to 5 PTMs & $\begin{array}{l}309 \text { peptides containing up } \\
\text { to } 4 \text { PTMs }\end{array}$ & $\begin{array}{l}121 \text { peptides containing up } \\
\text { to } 5 \text { PTMs }\end{array}$ \\
\hline & Histone variants & $\begin{array}{l}134 \text { peptides of } \mathrm{H} 3, \mathrm{H} 4, \mathrm{H} 2 \mathrm{~A}, \mathrm{H} 2 \mathrm{~B} \\
\text { and } \mathrm{H} 1 \text { variants }\end{array}$ & - & 4 peptides of H2A.X \\
\hline & Peptide length & 13 aа & 19 aа & $10-20$ aа \\
\hline & $\begin{array}{l}\text { Total number of } \\
\text { peptide species }\end{array}$ & 674 & 379 & 191 \\
\hline & Tiled sequence & $\checkmark$ & $\checkmark$ & - \\
\hline \multicolumn{2}{|l|}{ Spot replicates } & 3 spots $\times 2$ subarrays & 1 spot $\times 2$ subarrays & 6 spots $\times 4$ subarrays \\
\hline \multicolumn{2}{|c|}{ Dual-channel detection } & $\checkmark$ & - & $\checkmark$ \\
\hline
\end{tabular}

within the library (Figure 2A, Additional file 4: Figure S2 and Additional file 5: Figure S3). ATRX-ADD, AIRE-PHD and ING2-PHD bound three different PTM states, H3K9me3, H3K4unmod and H3K4me3, respectively, with no evident off-targets. By contrast, the two antibodies exhibited unsatisfactory sequence specificities. Most notably, there was dramatic off-target binding to H3K79me3 peptide using the H3K9me3 antibody (ab8898) and unexpected binding to H3K18me3 using the H3K4me3 antibody (ab8580) (Figure 2A and Additional file 5: Figure S3). Such cross-reactivity of histone antibodies at multiple sites is particularly concerning because the biological functions of histone PTMs are site-dependent and therefore confound the interpretation of antibody-dependent data. Collectively, our binding results further underscore specificity issues with histone antibodies and highlight the high specificity of the tested reader domains.

Within the same amino-acid sequence, the combinatorial PTM pattern is an important component of the chromatin landscape, and an appropriate enrichment strategy should select among diverse PTM states. Binding signals resulting from the same sequence were extracted from the microarray and the effects on coexisting (combinatorial) modifications in the $\mathrm{H} 3$ tail were assessed (Figure 2B). Modifications at R2 and $\mathrm{T} 3$ diminished binding of AIRE-PHD and ING2-PHD to the H3 tail (Figure 2B). For ATRX-ADD, K9me3 binding was abrogated by modifications at T3, T6 and R8 (Figure 2B). Most importantly, ATRX-ADD but not the antibody ab8898 discriminated against the bivalent peptide H3K4me3K9me3 (Figure 2B), suggesting that ATRX-ADD can uniquely enrich K4me0K9me3-containing chromatin. The strict specificity for K9me3 within the proper surrounding PTM state and a correct $\mathrm{N}$-terminal context (Figure 2B and Additional file 5: Figure S3) can be explained by the extensive interactions of ATRX-ADD with H3 1-10aa $[27,28]$. By comparison, the antibodies were less affected by surrounding residues and PTMs, failing to distinguish different PTM combinations (Figure 2B). We reasoned that the recognition specificity is largely dependent on the contact surface between the binding module (readers or antibodies) and its histone target. Reader modules with more surface interaction with the histone molecules, as we have shown here with ATRX-ADD, ING2-PHD, AIRE-PHD, will have longer sequence discrimination and therefore greater sensitivity to combinatorial PTMs within those contacts. For example, the linked domains of ATRX-ADD revealed increased binding specificity that results from the larger interaction surface with histone substrates (Figure 2).

Previous studies have demonstrated that reader domains interact with preferred histone substrates at low micromolar affinity [27-32], a range equal to or weaker than antibody recognition, which varies from micromolar to nanomolar [11]. To test whether such micromolar affinity is adequate for enriching specific nucleosomal PTMs, we next assessed the ability of ATRX-ADD to discriminate PTMs on a folded nucleosome structure, consisting of reconstituted mononucleosomes bearing either H3Kc4me3 or H3Kc9me3 (chemical analogs of H3K4me3 and H3K9me3 that permit stoichiometric modification). Consistent with the peptide microarray analysis, ATRX-ADD only exhibited binding with H3Kc9me3containing nucleosomes (Additional file 6: Figure S4). Furthermore, using standard Western blotting protocols, we demonstrate that ATRX-ADD can function as a highly specific probe to detect endogenous $\mathrm{H} 3 \mathrm{~K} 9 \mathrm{me} 3$ from cell lysate, showing sufficient affinity and specificity that rivals the corresponding antibody (Additional file 7: Figure S5).

We then evaluated whether the immobilized reader domains (MARCC approach) (Figure 3) captured unique chromatin states in native mononucleosomes from MCF-7 cells (Additional file 8: Figure S6). In this application, HaloTag provided an effective means of covalently linking the 

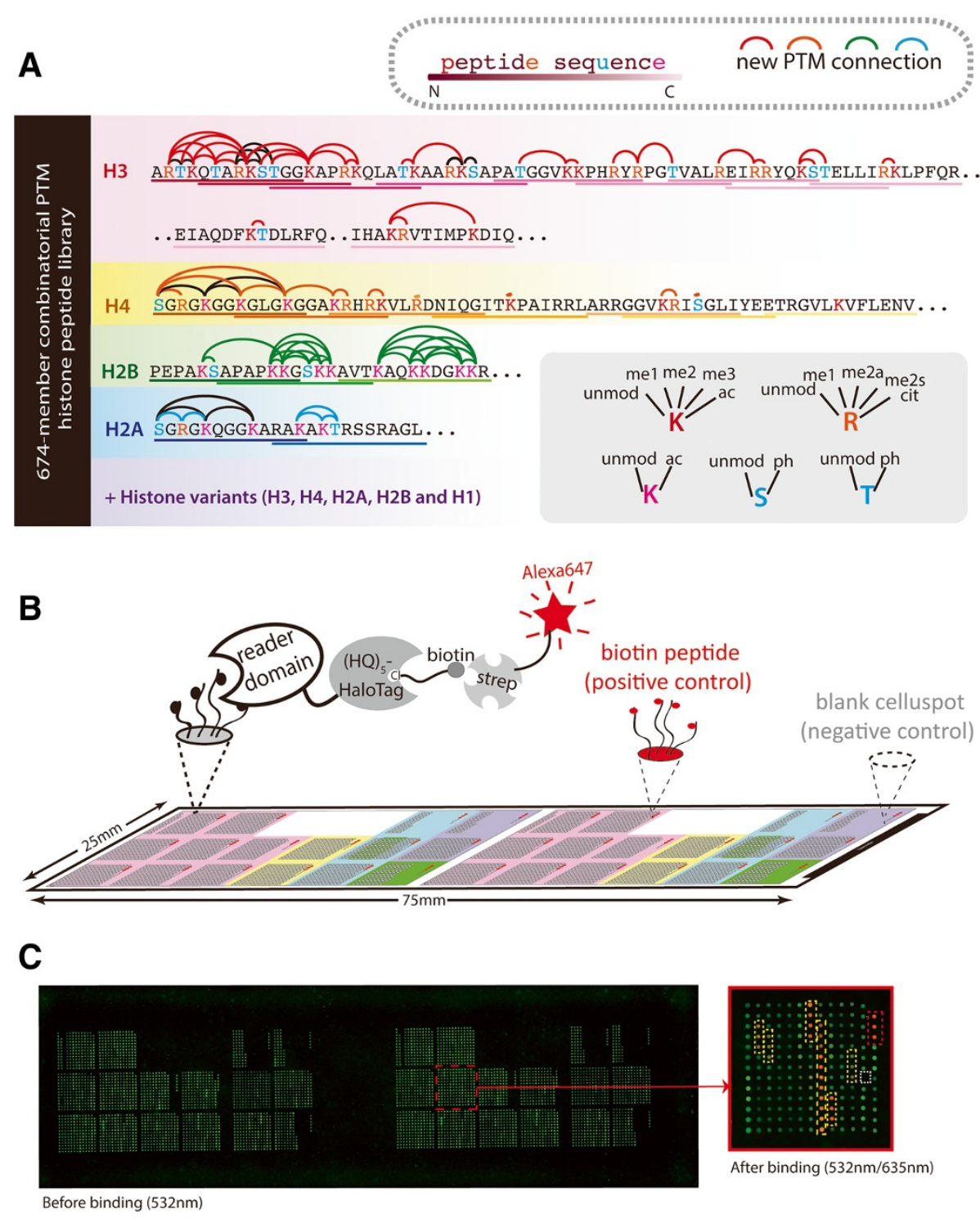

Figure 1 Design of the combinatorial PTM histone peptide microarray. (A) Construction of the combinatorial PTM peptide library. Combinatorial PTM histone peptide microarray featuring a tiled design and a high content of linked PTMs. Peptide sequence (underlined) covers core histones and histone variants; colored amino acids were modified according to the key. Colored arcs represent new PTM combinations and black arcs display PTM combinations used in previous arrays. (B) Histone peptide microarray binding assay. Peptides from Figure 1A were synthesized as cellulose conjugates and spatially spotted onto microarray, on which reader binding was detected and quantified by dual-channel fluorescence. Red star represents the binding signal at $635 \mathrm{~nm}$, which was used for reference binding intensities. (C) Layout of the combinatorial PTM histone peptide microarray. On the left is a representative image of an entire microarray before protein binding (detected at $532 \mathrm{~nm}$, green channel). On each microarray, two full libraries were included and each peptide was printed as triplicate spots. On the right is a zoom-in of a subarray from the big library detected at dual-channel $(532 \mathrm{~nm} / 635 \mathrm{~nm}$, green/red channel) after protein binding. On each subarray, biotin peptides were included as positive controls (boxed in red dashed line). Misprinting (boxed in white dashed line) can be easily identified from the green channel. Protein bindings (boxed in yellow dashed line) were quantified from the signal intensities at $635 \mathrm{~nm}$.

reader domains to a solid support, allowing extensive washing [36]. By Western blot analysis, MARCC revealed specific enrichment with each reader domain (Figure 4A,B): ING2-PHD enriched for H3K4me3-containing nucleosomes, AIRE-PHD discriminated against H3K4me3, and ATRX-ADD enriched H3K9me3-containing chromatin. To further define the chromatin states captured by MARCC, sufficient quantities of histone protein are required for quantitative mass spectrometry (qMS) while maintaining the native state of nucleosomes during enrichment. For this purpose, resin-captured nucleosomes from MARCC were released with tobacco etch virus (TEV) protease (Additional file 9: Figure S7) and analyzed by qMS. Owing to the low abundance of H3K4me3 $(<0.1 \%)$ in the input 

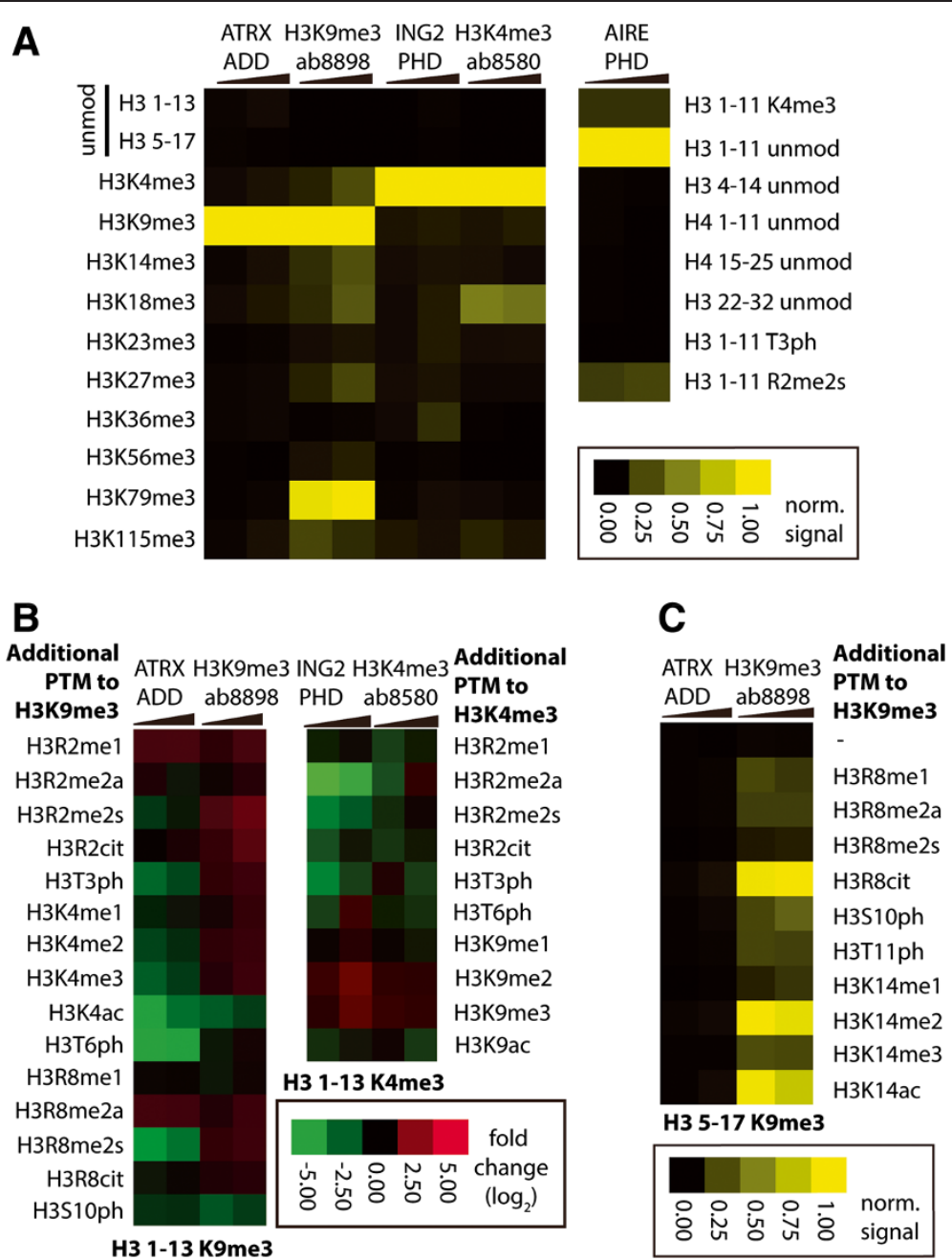

Figure 2 Histone peptide microarray analysis reveals high selectivity for amino-acid sequence and combinatorial PTM states by recombinant reader domains. (A-C) Heat map representation of binding specificity of reader fusions and histone antibodies determined from histone peptide microarrays. Reader fusions were probed on the slide at concentrations of $10 \mathrm{nM}$ to $500 \mathrm{nM}$ and antibodies were used as 1:10,000 to 1:2,000 dilution. (A) Effect of amino-acid sequence on binding. Averaged fluorescence signal intensities were normalized to the range between 0 and 1 by the lowest and the highest values of selected peptides for individual array. (B) Effect of combinatorial PTMs on binding. Averaged signal intensities for peptides with combinatorial PTMs were normalized to those with single modifications of interests as $\log _{2}$ ratio. (C) Correct N-terminal context is required for H3K9me3 binding by ATRX-ADD. The signal intensities of K9me3-containing peptides that covered H3 5 to 17 amino acids were quantified and normalized to the highest signals from individual arrays. ATRX-ADD domain was able to bind H3K9me3 peptides covering H3 1 to 13 aa (A) but not the peptides of H3 5 to 17 aa, whereas the antibody binds to both sequences.

chromatin, ING2-PHD MARCC enriched from $\approx 10^{7}$ cells was below the detection limit for qMS, though the high enrichment was evident by Western quantification and qPCR (Figure 4C).

Quantitative mass spectrometry (qMS) revealed unique nucleosomal PTM signatures of MARCC-enriched chromatin with excellent reproducibility (Additional file 10: Figure S8 B-D). Consistent with their direct binding sites, MARCC with AIRE-PHD enriched H3K4unmod-containing chromatin to $90 \%$ and MARCC with ATRX-ADD enriched both unmodified H3K4 and hypermethylated H3K9 to more than 90\% (Figure 4). Importantly, we were able to identify and quantify other PTM states that were co-enriched with the targeted PTM states (Figure 4 and Additional file 11: Table S1). Specifically, ATRX-ADD, but not AIRE-PHD, enriched H3K79unmod to over 90\% and H4K20me2/3 to $\approx 80 \%$, implying that these two modifications are more strongly associated with the combination of H3K4unmod and H3K9me2/3, but not H3K4unmod alone. In other words, ATRX-ADD captured specific heterochromatin state with four coexisting PTM signatures (H3K4unmod, H3K9me2/3, H4K20me2/3 and H3K79unmod), all of which were present at $>80 \%$ abundance, suggesting that most of these states exist on both histone copies within the mononucleosome. Previous ChIP-sequencing data have correlated H4K20 and H3K9 


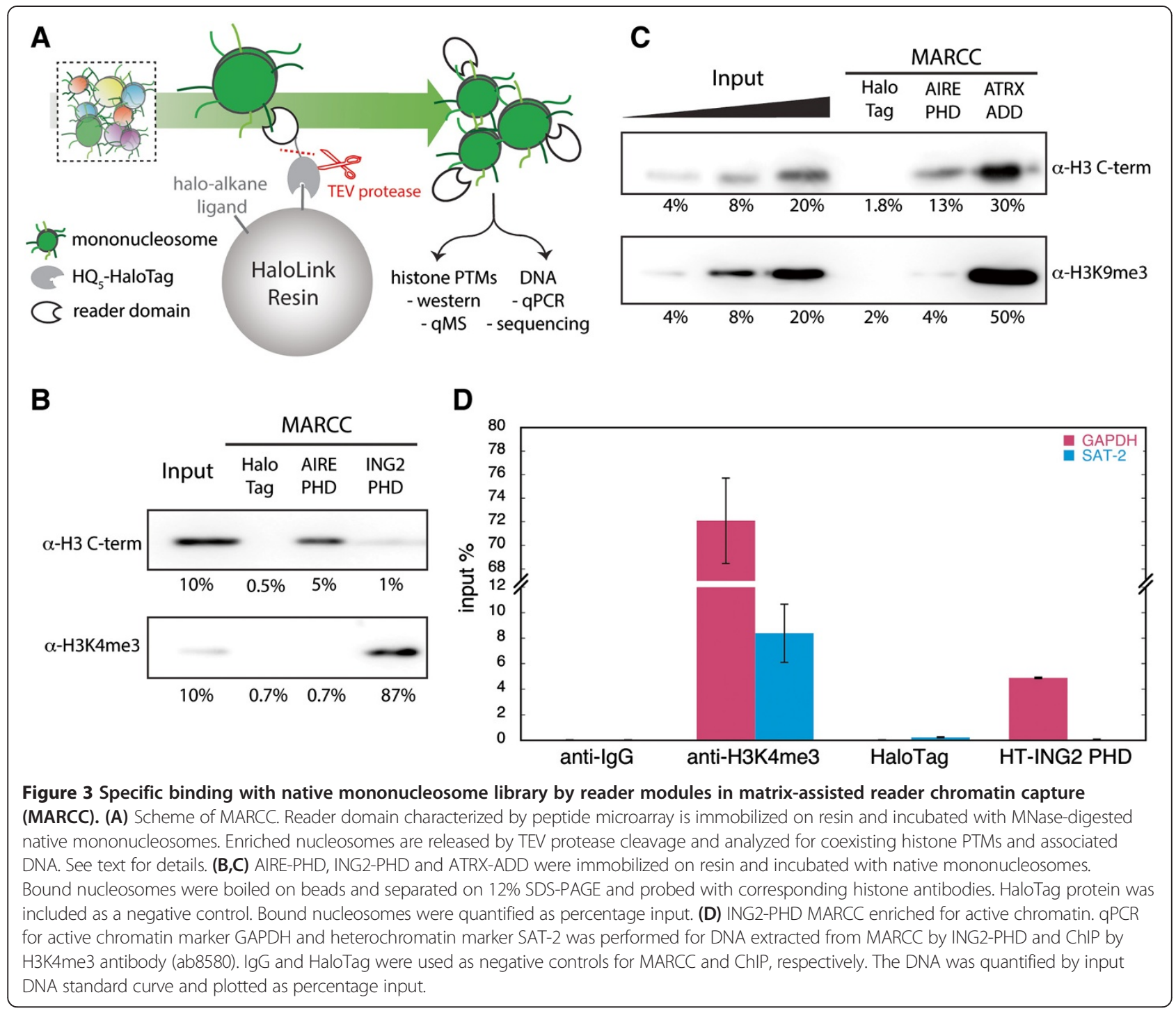

hypermethylation [37]. Here, our data suggest that these two modifications exist within the same nucleosome. One possibility is that the interaction between the H4K20 methyltransferase Suv4-20 and H3K9me3-binding protein HP1 [38] bridges the methyltransferase for intranucleosomal H4K20 methylation. H4K20 methylation is located near the basic batch of $\mathrm{H} 4$ [39] and might interfere with Dot1 (H3K79 methyltransferase), explaining the co-enrichment of H4K20 hypermethylation with unmodified H3K79. Still, the functional importance of these four PTMs coexisting at the mononucleosome level needs further investigation. We speculate that this combination might be enriched for a particular subtype of heterochromatin.

To support the hypothesis that ATRX-ADD enriched unique silent chromatin, relative enrichment of additional PTM signatures was quantified by qMS (Figure 5A). Similar analyses were performed with AIRE-PHD from the
MARCC enrichment (Figure 5B). We observed positive enrichment of repressive marks by ATRX-ADD, including H3K9 hypermethylation, H3K27 hypermethylation and H4K20 hypermethylation (Figure 5A, above $x$-axis). Consistent with silent chromatin, active marks such as $\mathrm{H} 4$ hyperacetylation and H3K36me3 were depleted by ATRXADD (Figure 5A, below $x$-axis). MARCC also provided information on less characterized PTMs, for example, methylations at H3K79 and H3K18. H3K79 methylation was dramatically depleted using MARCC with ATRXADD, indicating a negative correlation with this specific heterochromatin state. Strong enrichment of H3K18me1 by ATRX-ADD and AIRE-PHD (Figure 5A,B), which both strongly prefer H3K4unmod, suggests a role of this PTM in connection with H3K4unmod.

Finally, qPCR analysis of MARCC-eluted chromatin revealed highly enriched heterochromatic DNA by ATRXADD (Figure 5C). Collectively, these results suggest that 


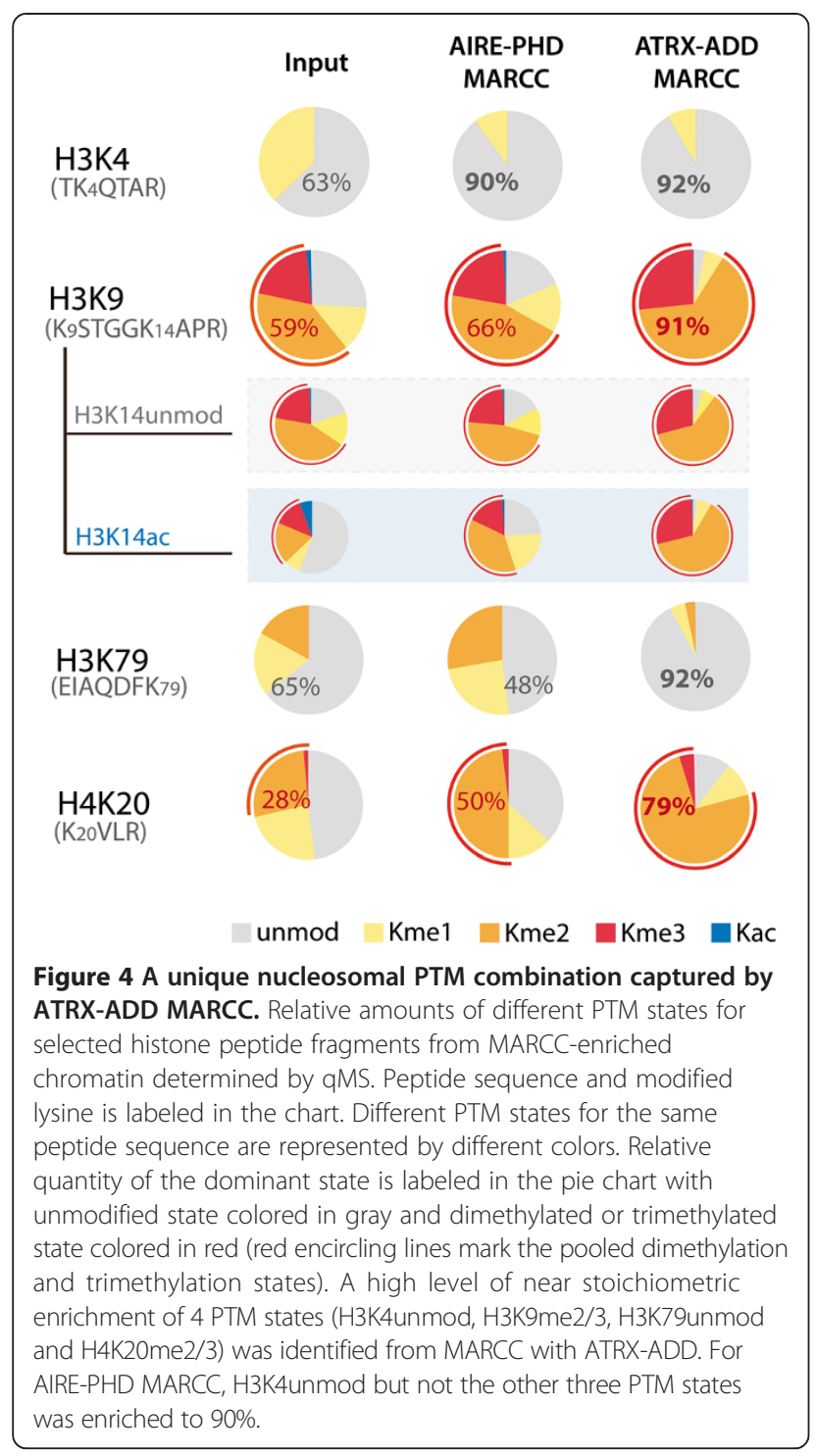

the combination of four coexisting nucleosomal PTMs enriched by ATRX-ADD represents a heterochromatic nucleosome species. The specificity of the enrichment and the combinatorial PTM signatures captured using MARCC with ATRX-ADD corroborates the application of MARCC as a tool to enrich, identify and quantify chromatin states with combinatorial PTM patterns and associated DNA.

\section{Conclusions}

In summary, we demonstrate an efficient, quantitative, reader-based platform for interrogating epigenetic states of chromatin (Table 1). The workflow involves (i) using a combinatorial PTM histone peptide microarray to define reader specificity and suitability for MARCC and (ii) utilization of MARCC to enrich, identify and quantify unique chromatin states. Utilizing this workflow, we describe three different reader domains that can recognize combinatorial PTM patterns and enrich unique chromatin states. Histone PTMs and their corresponding DNA associated with specific chromatin states are comprehensively profiled for as few as $10^{7}$ cells. Future systematic analyses of uncharacterized or genetically engineered readers will expand the capacity of MARCC to reveal undiscovered chromatin states. We envision that reader-based epigenetic platforms can function as a new paradigm for customizable chromatin enrichment reagents, avoiding issues of antibody variability and specificity.

\section{Methods \\ Plasmids}

Plasmids encoding mouse ING2-PHD (201 to 281) and human AIRE-PHD1 (293 to 354) were kindly provided by $\mathrm{T}$ Kutateladze (University of Colorado-Denver) and G Musco (Dulbecco Telethon Institute), respectively. cDNA encoding human ATRX-ADD (163 to 292) was synthesized (Integrated DNA Technologies, Inc.). A bacterial expression vector encoding an $\mathrm{N}$-terminal $(\mathrm{HQ})_{5}$-HaloTag followed by a TEV protease cleavage site was kindly supplied by Dr. M Slater and Dr. J Hartnett (Promega). A similar vector (pFN29) is now commercially available (Promega). ING2-PHD (200 to 280), AIRE-PHD (293 to 354) and ATRX-ADD (163 to 292) were amplified from the parent vectors and cloned into the $(\mathrm{HQ})_{5}$-HaloTag $\mathrm{N}$-terminal vector with SgfI and PmeI sites.

\section{Protein expression and purification}

All recombinant $(\mathrm{HQ})_{5}$-HaloTag fusion proteins and (HQ) ${ }_{5}$-HaloTag alone were expressed in BL21 (DE3) pLysS cells. When $\mathrm{OD}_{600 \mathrm{~nm}}$ reached 0.6 to 0.8 , expression was induced by addition of $0.5 \mathrm{mM}$ isopropyl $\beta$-D1-thiogalactopyranoside (IPTG) at 20 to $25^{\circ} \mathrm{C}$ for 4 hours or at $18^{\circ} \mathrm{C}$ overnight. $150 \mu \mathrm{M} \mathrm{ZnCl}$ was supplemented into the media after induction. The cell pellets were resuspended in $30 \mathrm{mM}$ HEPES, $500 \mathrm{mM} \mathrm{NaCl}, \mathrm{pH}$ 7.4, with $1 \mathrm{mM}$ dithiotheritol (DTT), $1 \mathrm{mM}$ phenylmethylsulfonyl fluoride (PMSF), $10 \mu \mathrm{g} / \mathrm{ml}$ leupeptin, $10 \mu \mathrm{g} / \mathrm{ml}$ aprotinin and $1 \mathrm{mg} / \mathrm{ml}$ lysozyme. After agitation at $4^{\circ} \mathrm{C}$ for $30 \mathrm{~min}$, the cell resuspension was further lysed by three mild sonication cycles $(20 \%$ amplitude; $5 \mathrm{~s}$ on; $5 \mathrm{~s}$ off; 1 min total per sonication cycle) with $1 / 4$ " probe (Thermo Fisher). Clarified lysate supernatant was incubated with Ni-NTA resin (GE Life Sciences) in batches for $2 \mathrm{~h}, 4^{\circ} \mathrm{C}$. Resin-bound proteins were washed three times with $30 \mathrm{mM}$ HEPES, $150 \mathrm{mM} \mathrm{NaCl}, 20 \mathrm{mM}$ imidazole, $\mathrm{pH}$ 7.4, followed by batch elution with $30 \mathrm{mM}$ HEPES, $150 \mathrm{mM} \mathrm{NaCl}, 300 \mathrm{mM}$ imidazole, $\mathrm{pH}$ 7.4. Eluents were dialyzed into $30 \mathrm{mM}$ HEPES, $150 \mathrm{mM} \mathrm{NaCl}$, $\mathrm{pH}$ 7.4, supplemented with $3 \mathrm{mM}$ DTT and up to $10 \%$ (v/v) glycerol. After being concentrated in $10 \mathrm{kDa}$ molecular weight cut-off (MWCO) Amicon (Millipore), protein 

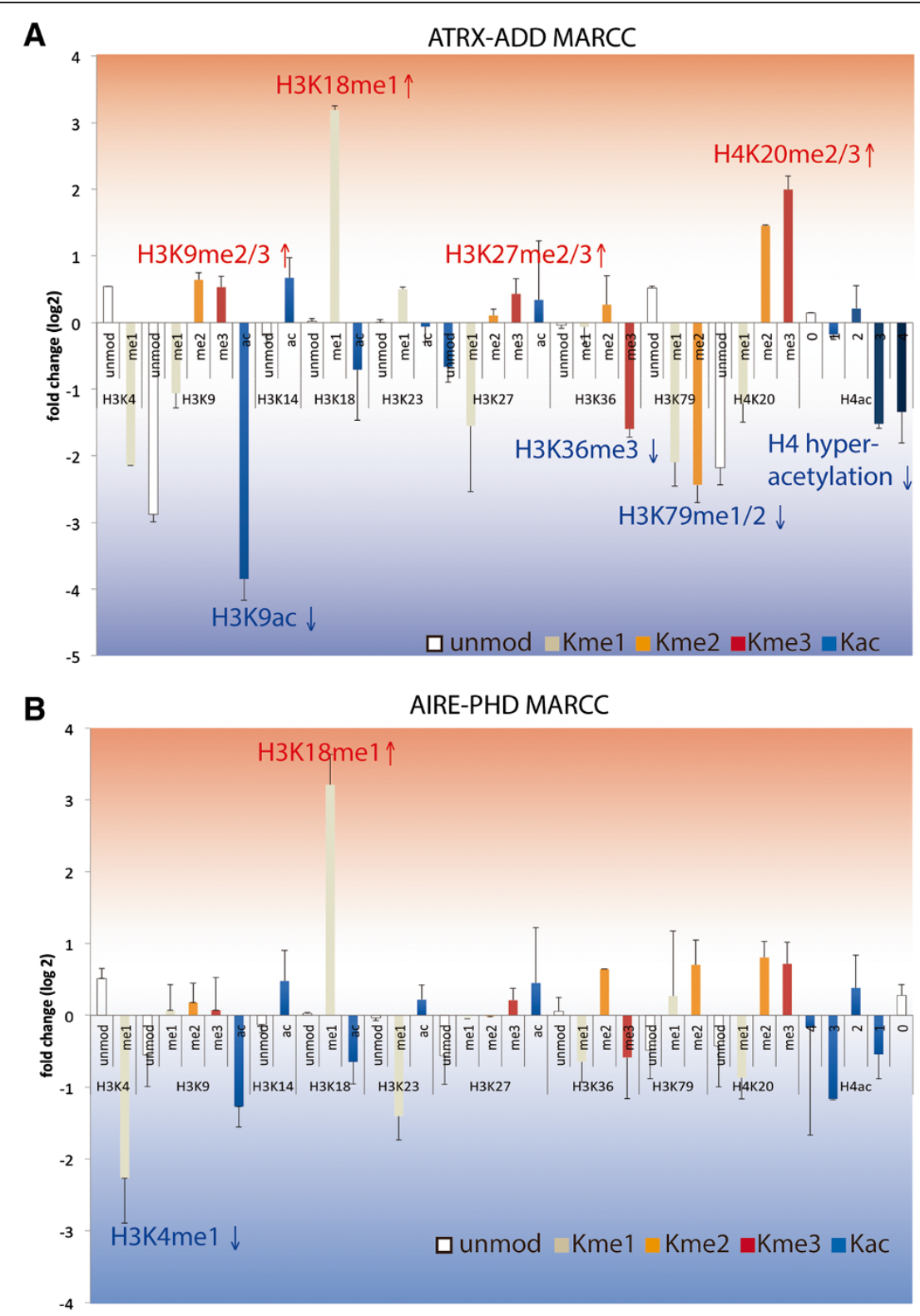

C

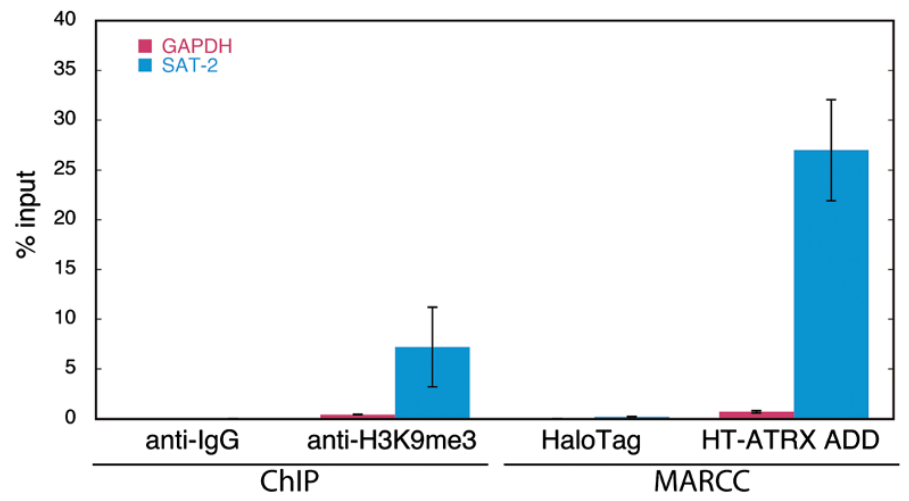

Figure 5 (See legend on next page.) 
(See figure on previous page.)

Figure 5 Quantitative profiling of chromatin PTM patterns identifies heterochromatic signature captured by MARCC with ATRX-ADD.

(A,B) Relative PTM enrichment with ATRX-ADD MARCC and AIRE-PHD MARCC. Relative enrichment was represented by $\log _{2}$ of the ratio of MARCC over input. PTM states above the $x$-axis were enriched by MARCC, whereas PTM states in the opposite direction were depleted by MARCC. Error bars were calculated from two separate MARCC-qMS experiments. For the complete qMS data set, refer to Additional file 11: Table S1. (C) Relative enrichment of heterochromatic DNA (SAT-2) by qPCR obtained from MARCC with ATRX-ADD. ChIP with H3K9me3 antibody (ab8898) or lgG and HaloTag were included as controls.

was quantified by Bradford assay and analyzed on $12 \%$ SDS-PAGE followed by Coomassie staining to check protein purity and integrity (Additional file 1: Figure S1A). Proteins were aliquoted and stored at $-80^{\circ} \mathrm{C}$.

\section{Combinatorial PTM histone peptide microarray synthesis}

Peptides were synthesized on modified cellulose with a Respep SL automated synthesizer (Intavis AG, Köln, Germany). A spotting control cellulose-Cy3 dye conjugate was created by simply removing Fmoc from the celluspot and coupling Cy3 (Lumiprobe, corp.). A blank celluspot control was created by deprotecting the Fmoc of the spot and subjecting the paper to the dissolution conditions. For peptides, the initial coupling consisted of equimolar amounts of Fmoc-Ala-OH and Boc-Ala-OH to decrease resin loading and improve synthesis quality. Each synthesis included peptides with an acid cleavable rink linker for quality assessment by HPLC and mass spectrometry (Additional file 12: Table S2). A 20-atom polyethylene linker (PE) was also included (Novabiochem), which improved synthesis and protein binding in the array. A streptavidin control was created by coupling Fmoc-Glu-(biotinyl-PEG)-OH (Novabiochem). Standard Fmoc/tBu chemistry was used to create the 13-amino-acid peptides. Peptide PTMs were introduced as suitably protected monomers, as described previously [24]. On completion of the synthesis, the side chain protecting groups were removed with $82.5 \%$ trifluoroacetic acid (TFA): $5 \%$ thioanisole: $5 \%$ water: $5 \%$ saturated phenol in dichloromethane: $2.5 \%$ ethane dithiol for 90 minutes (150 $\mu \mathrm{l}$ per spot). The solution was removed and replaced with $250 \mu \mathrm{l}$ of $88.5 \%$ TFA, $4 \%$ trifluoromethanesulfonic acid, $2.5 \%$ triisopropylsilane, $5 \%$ water and agitated gently overnight to dissolve the cellulose. Peptide cellulose conjugates were precipitated twice with cold diethyl ether, allowed to dry for several minutes, and redissolved into $100 \mu$ limethyl sulfoxide (DMSO).

The arrays were generated by combining $75 \%$ cellulose peptide DMSO solution with $10 \%$ cy3 cellulose and 15\% $7 \times$ saline-sodium citrate (SSC) buffer $(1.05 \mathrm{M} \mathrm{NaCl}$, $105 \mathrm{mM}$ sodium citrate). The biotin positive control was created by using $7.5 \%$ of the DMSO peptide stock solution with $67.5 \%$ DMSO in addition to the Cy3 cellulose conjugate and SSC buffer. Each solution was mixed in separate wells of 384-well polypropylene plates and spotted in triplicate onto $75 \mathrm{~mm} \times 25 \mathrm{~mm}$ nitrocellulose sides
(Intuitive Biosciences) with a Gene Machines OmniGrid Arrayer (Genomic Solutions). The dip time was $0 \mathrm{~ms}$ and the print time varied between 30 and 50 ms. Humidity and room temperature were controlled between $40 \%$ to $60 \%$ relative humidity and $20^{\circ} \mathrm{C}$ to $25^{\circ} \mathrm{C}$. A test microarray was printed and tested with HaloTag only or streptavidin only as a control to identify non-specific binding peptides, which were removed for subsequent microarrays (summarized in Additional file 2 and Additional file 12, Table S2). The final library contained 746 distinct histone peptide species. On each nitrocellulose slide, two identical libraries were printed, with each library containing 16 blocks and an overall number of 2,337 spots. In each block, blank cellulose spots and biotin peptide spots were included as negative and positive controls. The physical map of the peptide array is described in Additional file 2.

\section{Peptide array binding assay}

Peptide arrays were handled with care and protected from light. All solutions were filtered before putting on the array. Assays were performed with a modified twochamber simplex gasket (Intuitive Bioscience). After tightening the gasket onto the slide surface, the peptide array was blocked with blocking solution $(1 \times$ PBS, $0.05 \%$ Tween-20, pH 7.4, 1\% BSA) at $4^{\circ} \mathrm{C}$ overnight to reduce non-specific binding.

\section{For reader binding assay}

Purified recombinant $(\mathrm{HQ})_{5}$-HaloTag proteins $(10 \mathrm{nM}$ to $1 \mu \mathrm{M})$ were labeled with excessive HaloTag biotin ligand (Promega) in blocking solution and incubated with the peptide array under mild rocking at $4^{\circ} \mathrm{C}$ for 1 hour. The slide was washed with PBS with $0.05 \%$ Tween (PBST) three times and incubated with 1:2,000 streptavidin-conjugated Alexa-Fluor647 (Invitrogen) in blocking solution at room temperature for 1 hour.

\section{For antibody binding assay}

Different dilutions $(1: 10,000$ to $1: 2,000)$ of rabbit primary polyclonal antibodies (H3K9me3 antibody ab8898 lot\#GR102573-1, H3K4me3 antibody ab8580 lot\#GR561221 ) in blocking solution were incubated with the array under mild rocking at $4^{\circ} \mathrm{C}$ for 1 hour. The slide was washed with PBST three times and incubated with 1:1,000 anti-rabbit IgG Alexa 647 (Cell Signaling) in blocking solution at room temperature for 1 hour. 


\section{For both assays}

After three washes in PBST and a final wash in distilled water, the slide was dried by centrifugation and imaged at dual wavelengths of $532 \mathrm{~nm}$ and $635 \mathrm{~nm}$ on Axon GenePix 4000B (Molecular Devices). The laser power was set to $100 \%$, with automatic gain adjustment $(0.05 \%$ saturation tolerance) for dual photomultipliers. Image was obtained at $5 \mu \mathrm{m}$ pixel resolution. Features in each block were defined by manual adjustment of $13 \times 13$ grid (feature diameter, $280 \mu \mathrm{m}$; column spacing and row spacing, $320 \mu \mathrm{m})$ to cover every spot. Signal intensities were quantified by GenePix Pro 6.1 software (Molecular Devices). For each spot (feature), the mean intensities for $635 \mathrm{~nm}$ wavelength were used for subsequent analysis. For each peptide species, an average was calculated from three replicate spots. The averaged intensities were normalized to the range between 0 and 1 by the lowest and highest values of selected peptides on each library. For comparison between peptides with combinatorial modifications, the intensities were normalized to the peptide with single modification as $\log _{2}$ ratio. Heat maps were generated by Java Treeview version 1.1. The signal at $532 \mathrm{~nm}$ wavelength was used to identify misprinting events. For a complete dataset, see Additional file 3.

\section{Nucleosome reconstitution and MLA (methyl lysine analog) production}

Methyl lysine analog (MLA), $\mathrm{H}_{3} \mathrm{~K}_{\mathrm{c}} 4 \mathrm{me} 3\left(\mathrm{~K}_{\mathrm{c}}=\right.$ aminoethyl cysteine), was prepared according to the literature [40]. Briefly, Histone H3 (Xenopus laevis) with K4C and C110A mutations was expressed in Escherichia coli and purified by Superdex 200 column followed by ion-exchange columns. The purified histone was reduced, and the cysteine residue was alkylated with excess (2-bromoethyl) trimethylammonium bromide (Sigma Aldrich) at elevated temperature. After the reaction was quenched with 2mercaptoethanol, excess reagents and salts were removed using a PD-10 desalting device. Along with other core histones $(\mathrm{H} 2 \mathrm{~A}, \mathrm{H} 2 \mathrm{~B}$, and $\mathrm{H} 4)$ that are recombinantly prepared, $\mathrm{H}_{3} \mathrm{~K}_{\mathrm{c}} 4 \mathrm{me} 3 \mathrm{MLA}$ was refolded into histone octamers. The purified octamer and 146-bp DNA fragments (shown to exhibit strong positioning to the histone octamers) were reconstituted into nucleosome core particle by a salt-gradient dialysis method described previously [41].

\section{Reader-probe Western blot}

HEK293 cells were lysed in radioimmunoprecipitation assay (RIPA) buffer with protease inhibitors, nicotinamide and trichostatin A. The protein level was quantified by Bradford assay. $10 \mu \mathrm{g}$ total cell lysates were separated using 12\% SDS-PAGE and transferred to polyvinylidene fluoride (PVDF) membrane. After blocking with 5\% BSA for 1 hour at room temperature, the membrane was incubated with 100 nM HaloTag ATRX-ADD at $4^{\circ}$ for 3 hours.
Before incubation, ATRX-ADD was reacted with HaloTag ligand (biotin conjugate or AlexaFluor 660 conjugate) (Promega). For biotin conjugate, the membrane was further incubated with streptavidin-AlexaFluor647 conjugate (Invitrogen) at room temperature for 1 hour. After three washes, the membrane was directly exposed at Cy5 setting (GE ImageQuant LAS 4000).

\section{Native mononucleosome isolation from MCF-7 cells}

MCF-7 cells were cultured in DMEM supplemented with $10 \%$ FBS. For each nucleosome isolation, MCF-7 cells at $\approx 90 \%$ confluency from two 10 -cm plates $\left(\approx 2 \times 10^{7}\right.$ cells in total) were collected and washed for three times in ice-cold Buffer M (10 mM HEPES, $10 \mathrm{mM} \mathrm{KCl,} 1.5 \mathrm{mM}$ $\mathrm{MgCl}_{2}, 340 \mathrm{mM}$ sucrose, $\mathrm{pH}$ 7.9, 10\% glycerol, v/v), supplemented with $1 \mu \mathrm{g} / \mathrm{ml}$ trichostatin A, $1 \mathrm{mM}$ DTT, $0.5 \mathrm{mM}$ PMSF, $10 \mathrm{mM} \beta$-glycerophosphate, $1 \mathrm{mM}$ leupeptin, and $1 \mathrm{mM}$ aprotinin. At the last wash, the cell resuspension was lysed with $0.1 \%$ Triton X-100 on ice for $10 \mathrm{~min}$. After lysis, nuclei pellets were resuspended in Buffer $M$ and centrifuged at 1,300 $g$ for 12 min through chilled sucrose cushion buffer (10 mM HEPES, pH 7.9, $30 \%$ sucrose, w/v, $1.5 \mathrm{mM} \mathrm{MgCl}_{2}$ ) to further purify the nuclei pellets. After three washes with Buffer $M$, nuclei was diluted to 1.2 to $1.6 \mathrm{mg} / \mathrm{ml} \mathrm{DNA}$ concentration and digested with 2,000 gel units of micrococcal nuclease (New England Biolabs) at $37^{\circ} \mathrm{C}$ for $12 \mathrm{~min}$ with constant mixing in the presence of $1 \mathrm{mM}$ final concentration of $\mathrm{CaCl}_{2}$. Prior to assay, the amount of enzyme and digestion time was optimized to obtain above $90 \%$ purity of mononucleosomes. MNase activity was stopped with $10 \mathrm{mM}$ ethylenediaminetetraacetic acid (EDTA) and spun down. Soluble chromatin from the supernatant (S1) was collected. Less soluble chromatin (S2) was recovered from the nuclei pellets resuspended in $5 \mathrm{mM}$ HEPES, $0.2 \mathrm{mM}$ EDTA at $4^{\circ} \mathrm{C}$ overnight. Pooled chromatin extract (S1 plus S2) was concentrated to $\approx 10 \mu \mathrm{M}$ and dialyzed into 30 mM HEPES, 150 mM NaCl, pH 7.4, 10\% (v/v) glycerol. Nucleosomes were analyzed on $1.2 \%$ agarose gel (with $0.1 \%$ sodium dodecyl sulfate (SDS) in the sample) and $18 \%$ SDS-PAGE to check the size and quantity of DNA and histones separately (Additional file 1: Figure S1). A yield of $\approx 2$ nmole mononucleosomes (or $200 \mu \mathrm{g}$ DNA) was usually obtained from a single isolation.

\section{MARCC (matrix-assisted reader chromatin capture)}

The MARCC resins were prepared by incubation of saturating amounts (more than 10 nmole) of purified recombinant $(\mathrm{HQ})_{5}$-HaloTag proteins with $200 \mu \mathrm{l}$ HaloLink resin slurry (Promega) in MARCC buffer (30 mM HEPES, $150 \mathrm{mM} \mathrm{NaCl}, \mathrm{pH}$ 7.4, 0.01\% NP-40, 10\% glycerol) at $4^{\circ} \mathrm{C}$ for 1 hour. (HQ) $)_{5}$-HaloTag protein alone was included as a negative control. Excessive proteins were removed by three brief washes with MARCC buffer. 
Chromatin capture was achieved by incubating 1 nmole native mononucleosomes or reconstituted nucleosomes with MARCC resins under constant rotation at $4^{\circ} \mathrm{C}$ overnight. Bound chromatin was further washed with MARCC buffer and eluted by Halo-TEV protease (Promega) cleavage in the presence of $150 \mu \mathrm{l} 1 \mathrm{mM}$ Tris- $\mathrm{HCl}, \mathrm{pH} 7.4$ at room temperature for 2 hours. Eluted chromatin was combined with another $150 \mu \mathrm{l}$ resin-recovered chromatin and could be used for downstream analysis. For smallscale enrichment, 100 pmole nucleosomes and $20 \mu \mathrm{l}$ MARCC resin were used.

\section{Native chromatin immunoprecipitation (NChIP)}

100 pmole native mononucleosome extract was mixed with $2 \mu \mathrm{g}$ antibody (H3K4me3 - Ab8580, lot\# GR56122-1; H3K9me3 - Ab8898, lot\# GR102573-1; normal rabbit IgG - sc2027) and incubated with $20 \mu \mathrm{L}$ Magna ChIP Protein G magnetic beads (Millipore) in buffer $\mathrm{N}$ (30 mM HEPES, $150 \mathrm{mM} \mathrm{NaCl}, \mathrm{pH}$ 7.4, 0.01\% NP-40, 5 mM EDTA) under constant rotation at $4^{\circ} \mathrm{C}$ overnight. Bound chromatin was further washed with buffer $\mathrm{N}$ three times and eluted twice with $150 \mu$ l elution buffer containing $1 \%$ SDS.

\section{Quantitative mass spectrometry for histone PTMs}

Procedures for quantitative mass spectrometry sample preparation and data analysis were as previous described $[42,43]$. Briefly, histones were subjected to chemical derivatization using propionic anhydride (Sigma-Aldrich) and digested with sequencing grade trypsin (Promega) at a 10:1 substrate to enzyme ratio for 6 hours at $37^{\circ} \mathrm{C}$. The digested peptides were treated with an additional round of propionylation for the purpose of adding propionyl group to the newly generated $\mathrm{N}$-terminus. Peptides were desalted using $\mathrm{C} 18$ extracted mini disk (Empore $3 \mathrm{M}, \mathrm{MN}$, USA) and dissolved in $0.1 \%$ formic acid. Approximately $1 \mu \mathrm{g}$ of each sample was loaded via an autosampler (EASY-nLC, Thermo Fisher Scientific Inc.) onto a Thermo Scientific Acclaim PepMap 100 precolumn $(75 \mu \mathrm{m} \times 2 \mathrm{~cm}, \mathrm{C} 18$ resin, $3 \mu \mathrm{m}$ particle size, $100 \AA$ pore sizes). Peptides were chromatographically resolved via an Acclaim PepMap rapid separation liquid chromatography (RSLC) analytical column (50 $\mu \mathrm{m} \times$ $15 \mathrm{~cm}, \mathrm{C} 18$ resin, $2 \mu \mathrm{m}$ particle sizes, $100 \AA$ pore sizes), using a $67-$ min $1-98 \%$ solvent $\mathrm{B}$ gradient (solvent $\mathrm{A}=0.1 \%$ formic acid, solvent $\mathrm{B}=100 \%$ acetonitrile) at a flow rate of $300 \mathrm{nl} / \mathrm{min}$. The eluted peptides were electrosprayed into and detected by a Q Exactive mass spectrometer (Thermo Fisher Scientific Inc.) with a resolution of 70,000 for full MS spectrum followed by MS/MS spectra obtained in a higher-energy collisional dissociation cell. The relative abundance of each modification, expressed as a percentage on a histone peptide sequence, was quantified by analyzing its MS and MS/MS spectra via a program developed in-house. All results were also manually verified.

\section{DNA isolation and real-time PCR}

DNA was isolated from chromatin enriched by MARCC or NChIP along with $10 \%$ input chromatin using GeneJet PCR purification kit (Fermentas) in the presence of isopropanol. Real-time PCR was performed in duplicate with SsoFast EvaGreen supermix (Bio-Rad) on CFX96 (Bio-rad). For each specific PCR primer set, a standard curve was created from a serial dilution covering 0.2 to $5 \%$ of input DNA. For linear regression, Ct (cycle threshold) values were plotted with log starting quantity. Primer sets with $\mathrm{R}^{2}$ over 0.99 and amplification efficiency over $90 \%$ were chosen

$$
\text { efficiency }=10^{(-1 / \text { slope })}-1
$$

Nuclease-free water was used as a no-template control to monitor contaminants interfering with reactions. To quantify a specific DNA fragment in enriched chromatin samples, individual $\mathrm{Ct}$ values were converted into starting DNA quantity using corresponding standard curve and the average was calculated from two individual MARCC or ChIP experiments.

\section{Primer sets for qPCR}

1) GAPDH-forward: 5'-CAATTCCCCATCTCA GTCGT-3';

2) GAPDH-reverse: 5'-GCAGCAGGACACTAG GGAGT-3';

3) Chr1 SAT2-forward: 5'-CATCGATGGAAATG AAAGGAGTC-3';

4) Chr1 SAT2-reverse: 5' - ACCATTGGATGATTG CAGTCAA-3'.

\section{Additional files}

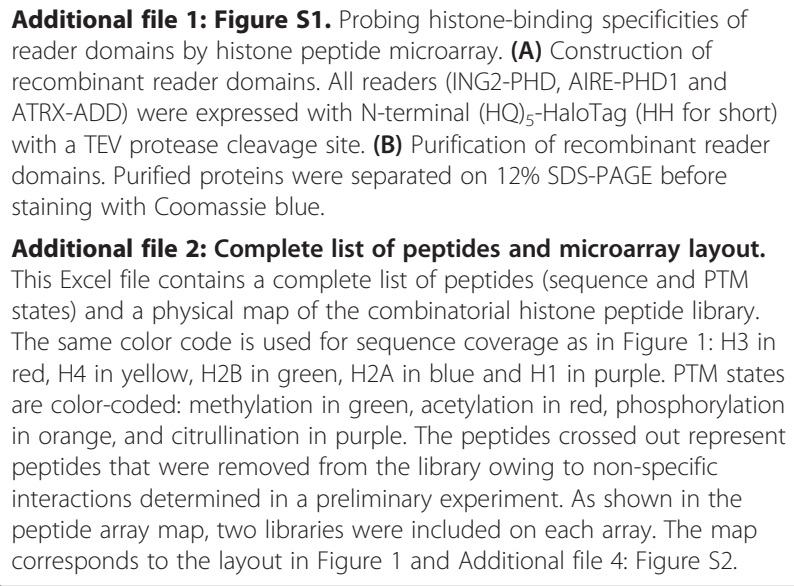

Additional file 2: Complete list of peptides and microarray layout. This Excel file contains a complete list of peptides (sequence and PTM states) and a physical map of the combinatorial histone peptide library. The same color code is used for sequence coverage as in Figure 1: $\mathrm{H3}$ in red, $\mathrm{H} 4$ in yellow, $\mathrm{H} 2 \mathrm{~B}$ in green, $\mathrm{H} 2 \mathrm{~A}$ in blue and $\mathrm{H} 1$ in purple. PTM states are color-coded: methylation in green, acetylation in red, phosphorylation in orange, and citrullination in purple. The peptides crossed out represent peptides that were removed from the library owing to non-specific interactions determined in a preliminary experiment. As shown in the peptide array map, two libraries were included on each array. The map corresponds to the layout in Figure 1 and Additional file 4: Figure S2. 
Additional file 3: Peptide microarray binding results. This Excel file contains the fluorescence signals from peptide microarray binding experiments. Raw signals and normalized intensities at $635 \mathrm{~nm}$ are included for specified concentrations of reader domains or histone antibodies from individual experiments. Average and standard deviations are derived from triplicate spots in each library ( - means that signal cannot be detected due to misprinting). The normalized values used to generate heat maps are also included.

Additional file 4: Figure S2. Histone peptide microarray images showed comparison of histone-binding specificity by reader modules and histone antibodies. The images were selected from representative arrays. $500 \mathrm{nM}$ purified HH-ATRX-ADD (A), 1:10,000 diluted H3K9me3 antibody (B), $10 \mathrm{nM}$ purified HH-ING2-PHD (C) or 1:10,000 diluted H3K4me3 antibody (D) were incubated with histone peptide array. The green channel signal $(532 \mathrm{~nm}$ ) for Cy3 tracer dye was used to identify misprinting (boxed in white dashed line). The red channel signal $(635 \mathrm{~nm})$ of Alexa647 was used to quantify binding intensities. Both primary targets and off-targets were boxed and labeled on the image. For peptide array design and mapping, refer to Additional file 2.

Additional file 5: Figure S3. Specific amino-acid sequence and combinatorial PTM pattern recognized by reader domains. The signal intensities were quantified from the images from Additional file 3 scanned at $635 \mathrm{~nm}$ by Axon GenePix 4000B. Signal intensities were averaged from three replicate spots for the same peptide and normalized to the highest signal on individual array. Peptides covered selective sites of interests with combinations of primary PTMs (colored red in the sequence) and secondary PTMs on nearby residues (colored green in the sequence).

Additional file 6: Figure S4. ATRX-ADD exhibited specific binding with MLA reconstituted nucleosomes. (A) Reconstituted nucleosomes with wildtype $\mathrm{H} 3$ (wildtype) or nucleosomes harboring H3K4C-me3 or H3K9C-me3 MLA modifications were probed with H3K4me3 or H3K9me3 antibodies, or Coomassie stained. (B) HaloTag-ATRX-ADD was immobilized on HaloLink resin and incubated with reconstituted nucleosomes. After several washes, bound nucleosomes were boiled on beads, separated using 12\% SDS-PAGE and probed with H3 C-term antibody (ab46765). HaloTag protein was included as a negative control. Bound nucleosomes were compared with $10 \%$ input for each species of nucleosomes.

Additional file 7: Figure S5. H3-specific binding of ATRX-ADD from cell lysate. In a standard Western blot procedure, $10 \mu \mathrm{g}$ of two separately prepared HEK293 cell lysates were separated using 12\% SDS-PAGE and transferred to a PVDF membrane. After blocking the membrane with 5\% BSA, 100 nM HH-ATRX-ADD (labeled with HaloTag ligand-biotin as in Figure S5A, or labeled with HaloTag ligand-Alexa 660 as in Figure S5B) was incubated with the membrane at $4^{\circ}$ for 3 hours. (B) After several washes, the membrane was directly detected at Cy5 setting (GE ImageQuant LAS 4000). For Figure S5A, the membrane was further incubated with 1:2000 streptavidin-Alexa647 at room temperature for 1 hour before detected at Cy5 setting. For comparison, traditional antibody-based Western blot was performed with 1:5,000 anti-H3K9me3 (ab8898) with 1:5,000 goat-anti-rabbit-HRP, detected by SuperSignal West Dura kit (Pierce) (Figure S5C).

Additional file 8: Figure S6. Preparation of native mononucleosome library. (A) Schematic illustration of native mononucleosome library preparation. Cells were pelleted and lysed to isolate nuclei. Nuclei were then digested by micrococcal nuclease to generate mononucleosomes in the soluble fractions. $(\mathbf{B}, \mathbf{C})$ Preparation of mononucleosome library by MNase digestion. Nuclei were digested with MNase and the reaction was stopped at different time points (0, 1, 3, 6, 9 and $12 \mathrm{~min}$ ) by addition of EDTA. The digested chromatin was supplemented with $0.1 \% \mathrm{SDS}(\mathrm{w} / \mathrm{V}$, final) and run on $1.2 \%$ agarose gel at $2 \mathrm{~V} / \mathrm{cm}$ for 6 hours before staining with ethidium bromide. S1: soluble fraction 1; S2: soluble fraction 2; P: precipitation. After $12 \mathrm{~min}$, the pooled soluble fractions (S1 + S2) were mostly mononucleosomes (>95\%). (D) Protein purity and reproducibility of native mononucleosome library preparations. Two independent preparations of native MCF-7 mononucleosome library were run on 18\% SDS-PAGE gel and stained with Coomassie blue.

Additional file 9: Figure S7. Preparation, capture and elution of customized MARCC resin. (A) Release of reader domains by TEV cleavage on resin. ATRX-ADD domain was cleaved off the resin by incubating immobilized HH-ATRX-ADD with HaloTEV protease. FT, flow-through; E1, elution 1; E2, elution 2; bead, resin after elution. $(\mathbf{B}, \mathbf{C})$ Elution by TEV cleavage yields intact mononucleosomes for downstream analysis. Histones (B) and DNA (C) were resolved on gel. Glycine elution did not achieve similar elution efficiency to TEV cleavage. (D) DNA purified from AIRE-PHD, ING2-PHD and ATRX-ADD MARCC enrichment was run on 1\% agarose gel. The DNA size was enriched at $146 \mathrm{bp}$.

Additional file 10: Figure S8. MARCC-enriched chromatin reveals coexisting PTM patterns. (A) Peptide sequence coverage with associated PTMs of GMS used in this study. (B) Comparison of input chromatin used in this study with previous dataset [44]. (C,D) Reproducibility of qMS quantifications for MARCCS by AIRE-PHD and ATRX-ADD. Linear correlation of the same peptide species from two independent MARCC-qMS assays were calculated.

Additional file 11: Table S1. Quantitative assessment of combinatorial histone PTM patterns by MARCC-qMS.

Additional file 12: Table S2. Quality control data for peptides from peptide microarray.

\section{Abbreviations}

AIRE: autoimmune regulator; ATRX: alpha-thalassemia/mental retardation, X-linked; ADD: ATRX-DNMT3-DNMT3L; BSA: bovine serum albumin; ChIP: chromatin immunoprecipitation; Ct: cycle threshold; DMEM: Dulbecco's modified Eagle's medium; DMSO: dimethyl sulfoxide; DTT: dithiotheritol; EDTA: ethylenediaminetetraacetic acid; FBS: fetal bovine serum; H3K4me3: histone $\mathrm{H3}$ trimethylated at lysine 4; H3K9me3: histone H3 trimethylated at lysine 9; $\mathrm{HH}$ : (HQ) $)_{5}$-HaloTag; HPLC: high-performance liquid chromatography; IgG: immunoglobulin G; ING: inhibitor of growth; IPTG: isopropyl $\beta$-D-1-thiogalactopyranoside; $K_{c}$ : aminoethyl cysteine; MARCC: matrix-assisted reader chromatin capture; MCF-7: Michigan Cancer Foundation-7; MLA: methyl lysine analog; MNase: micrococcal nuclease; MS: mass spectrometry; MWCO: molecular weight cut-off; NChIP: native chromatin immunoprecipitation; OD: optical density; PBS: phosphate-buffered saline; PBST: phosphate-buffered saline with Tween; PCR: polymerase chain reaction; PE: polyethylene linker; PHD: plant homeodomain; PMSF: phenylmethylsulfonyl fluoride; PTM: post-translational modification; PVDF: polyvinylidene fluoride; GMS: quantitative mass spectrometry; qPCR: quantitative polymerase chain reaction; RSLC: rapid separation liquid chromatography; SDS: sodium dodecyl sulfate; SSC: saline-sodium citrate; TEV: tobacco etch virus; TFA: trifluoroacetic acid.

\section{Competing interests}

The authors declare that they have no competing interests.

\section{Authors' contributions}

ZS and JMD conceived and designed the overall study. SSO, ZS, MDB and $J H L$ designed the histone peptide array layout. MDB synthesized the peptides and printed the peptide arrays. ZS carried out the experiments and analyzed the results. JHL synthesized the MLA nucleosomes. SL and BAG performed the GMS analysis. ZS and JMD wrote the manuscript. All authors read and approved the final manuscript.

\section{Acknowledgements}

We are grateful to former laboratory members E Wagner and B Albaugh for cloning the corresponding constructs. We thank R Sridharan, $X$ Zhong, P Lewis and E Wagner (University of Wisconsin-Madison) for helpful discussion and critical reading of the manuscript. We also thank Gene Expression Center (University of Wisconsin Biotechnology Center) for technical assistance with peptide array printing and scanning and W Xu (University of Wisconsin-Madison) for sharing MCF-7 cells. This research is supported by NIH R01 grant \#2R37GM059785-15/P250VA (JMD), National Science Foundation Early Faculty CAREER award (BAG) and an NIH Innovator grant (DP2OD007447) from the Office of the Director (BAG). 


\section{Author details}

${ }^{1}$ Department of Biomolecular Chemistry, University of Wisconsin, Madison, WI 53706, USA. ${ }^{2}$ Wisconsin Institute for Discovery, University of Wisconsin, Madison, WI 53715, USA. ${ }^{3}$ Biotechnology Center, University of Wisconsin, Madison, WI 53706, USA. ${ }^{4}$ Perelman School of Medicine, University of Pennsylvania, Philadelphia, PA 19104, USA.

\section{Received: 23 January 2014 Accepted: 9 April 2014}

Published: 24 April 2014

\section{References}

1. Strahl BD, Allis CD: The language of covalent histone modifications. Nature 2000, 403(6765):41-45

2. Voigt P, LeRoy G, Drury WJ III, Zee BM, Son J, Beck DB, Young NL, Garcia BA, Reinberg D: Asymmetrically modified nucleosomes. Cell 2012, 151(1):181-193.

3. Fischle W, Tseng BS, Dormann HL, Ueberheide BM, Garcia BA, Shabanowitz J, Hunt DF, Funabiki H, Allis CD: Regulation of HP1-chromatin binding by histone $\mathrm{H} 3$ methylation and phosphorylation. Nature 2005 438(7071):1116-1122.

4. Young NL, DiMaggio PA, Plazas-Mayorca MD, Baliban RC, Floudas CA, Garcia BA: High throughput characterization of combinatorial histone codes. Mol Cell Proteomics 2009, 8(10):2266-2284.

5. Phanstiel D, Brumbaugh J, Berggren WT, Conard K, Feng X, Levenstein ME, McAlister GC, Thomson JA, Coon JJ: Mass spectrometry identifies and quantifies 74 unique histone $\mathrm{H} 4$ isoforms in differentiating human embryonic stem cells. Proc Natl Acad Sci U S A 2008, 105(11):4093-4098.

6. Fuchs SM, Krajewski K, Baker RW, Miller VL, Strahl BD: Influence of combinatorial histone modifications on antibody and effector protein recognition. Curr Biol 2011, 21(1):53-58.

7. Bock I, Dhayalan A, Kudithipudi S, Brandt O, Rathert P, Jeltsch A: Detailed specificity analysis of antibodies binding to modified histone tails with peptide arrays. Epigenetics 2011, 6(2):256-263.

8. Bua DJ, Kuo AJ, Cheung P, Liu CL, Migliori V, Espejo A, Casadio F, Bassi C, Amati B, Bedford MT, Guccione E, Gozani O: Epigenome microarray platform for proteome-wide dissection of chromatin-signaling networks. Plos One 2009, 4(8):e6789.

9. Egelhofer TA, Minoda A, Klugman S, Lee K, Kolasinska-Zwierz P, Alekseyenko AA, Cheung MS, Day DS, Gadel S, Gorchakov AA, Gu T, Kharchenko PV, Kuan S, Latorre I, Linder-Basso D, Luu Y, Ngo Q, Perry M, Rechtsteiner A, Riddle NC, Schwartz YB, Shanower GA, Vielle A, Ahringer J, Elgin SC, Kuroda MI, Pirrotta V, Ren B, Strome S, Park PJ, et al: An assessment of histone-modification antibody quality. Nat Struct Mol Biol 2011, 18(1):91-93.

10. Heubach Y, Planatscher H, Sommersdorf C, Maisch D, Maier J, Joos TO, Templin MF, Poetz O: From spots to beads-PTM-peptide bead arrays for the characterization of anti-histone antibodies. Proteomics 2013, 13(6):1010-1015.

11. Nishikori S, Hattori T, Fuchs SM, Yasui N, Wojcik J, Koide A, Strahl BD, Koide $S$ : Broad ranges of affinity and specificity of anti-histone antibodies revealed by a quantitative peptide immunoprecipitation assay. $J \mathrm{Mol}$ Biol 2012, 424(5):391-399.

12. Hattori T, Taft JM, Swist KM, Luo H, Witt H, Slattery M, Koide A, Ruthenburg AJ, Krajewski K, Strahl BD, White KP, Farnham PJ, Zhao Y, Koide S: Recombinant antibodies to histone post-translational modifications. Nat Methods 2013, 10(10):992-995.

13. Fuchs SM, Strahl BD: Antibody recognition of histone post-translational modifications: emerging issues and future prospects. Epigenomics 2011, 3(3):247-249.

14. Ernst J, Kellis M: Discovery and characterization of chromatin states for systematic annotation of the human genome. Nat Biotechnol 2010, 28(8):817-825.

15. Kharchenko PV, Alekseyenko AA, Schwartz YB, Minoda A, Riddle NC, Ernst J, Sabo PJ, Larschan E, Gorchakov AA, Gu T, Linder-Basso D, Plachetka A, Shanower G, Tolstorukov MY, Luquette L, Xi R, Jung YL, Park RW, Bishop EP Canfield TK, Sandstrom R, Thurman RE, MacAlpine DM, Stamatoyannopoulos JA, Kellis M, Elgin SC, Kuroda MI, Pirrotta V, Karpen GH, Park PJ: Comprehensive analysis of the chromatin landscape in Drosophila melanogaster. Nature 2011, 471(7339):480-485.

16. Ernst J, Kheradpour $P$, Mikkelsen TS, Shoresh N, Ward LD, Epstein CB, Zhang X, Wang L, Issner R, Coyne M, Ku M, Durham T, Kellis M, Bernstein BE:
Mapping and analysis of chromatin state dynamics in nine human cell types. Nature 2011, 473(7345):43-49.

17. Mikkelsen TS, Ku M, Jaffe DB, Issac B, Lieberman E, Giannoukos G, Alvarez P, Brockman W, Kim TK, Koche RP, Lee W, Mendenhall E, O'Donovan A, Presser A, Russ C, Xie X, Meissner A, Wernig M, Jaenisch R, Nusbaum C, Lander ES, Bernstein BE: Genome-wide maps of chromatin state in pluripotent and lineage-committed cells. Nature 2007, 448(7153):553-560.

18. Zhu J, Adli M, Zou JY, Verstappen G, Coyne M, Zhang X, Durham T, Miri M, Deshpande V, De Jager PL, Bennett DA, Houmard JA, Muoio DM, Onder TT, Camahort R, Cowan CA, Meissner A, Epstein CB, Shoresh N, Bernstein BE: Genome-wide chromatin state transitions associated with developmental and environmental cues. Cell 2013, 152(3):642-654

19. Bernstein BE, Mikkelsen TS, Xie X, Kamal M, Huebert DJ, Cuff J, Fry B, Meissner A, Wernig M, Plath K, Jaenisch R, Wagschal A, Feil R, Schreiber SL, Lander ES: A bivalent chromatin structure marks key developmental genes in embryonic stem cells. Cell 2006, 125(2):315-326.

20. van Rossum B, Fischle W, Selenko P: Asymmetrically modified nucleosomes expand the histone code. Nat Struct Mol Biol 2012, 19(11):1064-1066

21. Peach SE, Rudomin EL, Udeshi ND, Carr SA, Jaffe JD: Quantitative assessment of chromatin immunoprecipitation grade antibodies directed against histone modifications reveals patterns of co-occurring marks on histone protein molecules. Mol Cell Proteomics 2012, 11(5):128-137.

22. Soldi $M$, Bonaldi $\mathrm{T}$ : The proteomic investigation of chromatin functional domains reveals novel synergisms among distinct heterochromatin components. Mol Cell Proteomics 2013, 12(3):764-780.

23. Musselman CA, Lalonde ME, Cote J, Kutateladze TG: Perceiving the epigenetic landscape through histone readers. Nat Struct Mol Biol 2012, 19(12):1218-1227.

24. Garske AL, Oliver SS, Wagner EK, Musselman CA, LeRoy G, Garcia BA Kutateladze TG, Denu JM: Combinatorial profiling of chromatin binding modules reveals multisite discrimination. Nat Chem Biol 2010, 6(4):283-290.

25. Vermeulen M, Mulder KW, Denissov S, Pijnappel WW, van Schaik FM, Varier RA, Baltissen MP, Stunnenberg HG, Mann M, Timmers HT: Selective anchoring of TFIID to nucleosomes by trimethylation of histone $\mathrm{H} 3$ lysine 4. Cell 2007, 131(1):58-69.

26. Moore KE, Carlson SM, Camp ND, Cheung P, James RG, Chua KF Wolf-Yadlin A, Gozani O: A general molecular affinity strategy for global detection and proteomic analysis of lysine methylation. Mol Cell 2013, 50(3):444-456.

27. Eustermann S, Yang JC, Law MJ, Amos R, Chapman LM, Jelinska C, Garrick D, Clynes D, Gibbons RJ, Rhodes D, Higgs DR, Neuhaus D: Combinatorial readout of histone $\mathrm{H} 3$ modifications specifies localization of ATRX to heterochromatin. Nat Struct Mol Biol 2011, 18(7):777-782.

28. Iwase S, Xiang B, Ghosh S, Ren T, Lewis PW, Cochrane JC, Allis CD, Picketts DJ, Patel DJ, Li H, Shi Y: ATRX ADD domain links an atypical histone methylation recognition mechanism to human mental-retardation syndrome. Nat Struct Mol Biol 2011, 18(7):769-776.

29. Pena PV, Davrazou F, Shi X, Walter KL, Verkhusha W, Gozani O, Zhao R, Kutateladze TG: Molecular mechanism of histone H3K4me3 recognition by plant homeodomain of ING2. Nature 2006, 442(7098):100-103.

30. Shi $X$, Hong $T$, Walter $K L$, Ewalt M, Michishita E, Hung T, Carney D, Pena P, Lan F, Kaadige MR, Lacoste N, Cayrou C, Davrazou F, Saha A, Cairns BR, Ayer DE, Kutateladze TG, Shi Y, Côté J, Chua KF, Gozani O: ING2 PHD domain links histone $\mathrm{H} 3$ lysine 4 methylation to active gene repression. Nature 2006, 442(7098):96-99.

31. Chakravarty S, Zeng L, Zhou MM: Structure and site-specific recognition of histone $\mathrm{H} 3$ by the PHD finger of human autoimmune regulator. Structure 2009, 17(5):670-679.

32. Chignola F, Gaetani M, Rebane A, Org T, Mollica L, Zucchelli C, Spitaleri A, Mannella V, Peterson P, Musco G: The solution structure of the first PHD finger of autoimmune regulator in complex with non-modified histone $\mathrm{H} 3$ tail reveals the antagonistic role of H3R2 methylation. Nucleic Acids Res 2009, 37(9):2951-2961.

33. Bock I, Kudithipudi S, Tamas R, Kungulovski G, Dhayalan A, Jeltsch A: Application of Celluspots peptide arrays for the analysis of the binding specificity of epigenetic reading domains to modified histone tails. BMC Biochem 2011, 12:48. 
34. Rothbart SB, Dickson BM, Ong MS, Krajewski K, Houliston S, Kireev DB, Arrowsmith $\mathrm{CH}$, Strahl BD: Multivalent histone engagement by the linked tandem Tudor and PHD domains of UHRF1 is required for the epigenetic inheritance of DNA methylation. Genes Dev 2013, 27(11):1288-1298.

35. Cai L, Rothbart SB, Lu R, Xu B, Chen WY, Tripathy A, Rockowitz S, Zheng D, Patel DJ, Allis CD, Strahl BD, Song J, Wang GG: An H3K36 methylation-engaging Tudor motif of polycomb-like proteins mediates PRC2 complex targeting. Mol Cell 2013, 49(3):571-582.

36. Los GV, Encell LP, McDougall MG, Hartzell DD, Karassina N, Zimprich C, Wood MG, Learish R, Ohana RF, Urh M, Simpson D, Mendez J, Zimmerman K, Otto P, Vidugiris G, Zhu J, Darzins A, Klaubert DH, Bulleit RF, Wood KV: HaloTag: a novel protein labeling technology for cell imaging and protein analysis. ACS Chem Biol 2008, 3(6):373-382.

37. Barski A, Cuddapah S, Cui K, Roh TY, Schones DE, Wang Z, Wei G, Chepelev I, Zhao K: High-resolution profiling of histone methylations in the human genome. Cell 2007, 129(4):823-837.

38. Schotta G, Lachner M, Sarma K, Ebert A, Sengupta R, Reuter G, Reinberg $D$, Jenuwein $\mathrm{T}$ : A silencing pathway to induce $\mathrm{H} 3-\mathrm{K} 9$ and H4-K20 trimethylation at constitutive heterochromatin. Genes Dev 2004, 18(11):1251-1262.

39. Fingerman IM, Li HC, Briggs SD: A charge-based interaction between histone $\mathrm{H} 4$ and Dot 1 is required for H3K79 methylation and telomere silencing: identification of a new trans-histone pathway. Genes Dev 2007, 21(16):2018-2029.

40. Simon MD, Chu F, Racki LR, de la Cruz CC, Burlingame AL, Panning B, Narlikar GJ, Shokat KM: The site-specific installation of methyl-lysine analogs into recombinant histones. Cell 2007, 128(5):1003-1012.

41. Luger K, Rechsteiner TJ, Richmond TJ: Preparation of nucleosome core particle from recombinant histones. Methods Enzymol 1999, 304:3-19.

42. Plazas-Mayorca MD, Zee BM, Young NL, Fingerman IM, LeRoy G, Briggs SD Garcia BA: One-pot shotgun quantitative mass spectrometry characterization of histones. J Proteome Res 2009, 8(11):5367-5374.

43. Garcia BA, Mollah S, Ueberheide BM, Busby SA, Muratore TL, Shabanowitz J, Hunt DF: Chemical derivatization of histones for facilitated analysis by mass spectrometry. Nat Protoc 2007, 2(4):933-938.

44. Leroy G, Dimaggio PA, Chan EY, Zee BM, Blanco MA, Bryant B, Flaniken IZ, Liu S, Kang Y, Trojer P, Garcia BA: A quantitative atlas of histone modification signatures from human cancer cells. Epigenetics Chromatin 2013, 6(1):20.

doi:10.1186/1756-8935-7-7

Cite this article as: Su et al:: ChIP-less analysis of chromatin states.

Epigenetics \& Chromatin 2014 7:7.

\section{Submit your next manuscript to BioMed Central and take full advantage of:}

- Convenient online submission

- Thorough peer review

- No space constraints or color figure charges

- Immediate publication on acceptance

- Inclusion in PubMed, CAS, Scopus and Google Scholar

- Research which is freely available for redistribution 